\title{
Oxygen and ${ }^{99 \mathrm{~m}}$ Tc-MAA shunt estimations in patients with pulmonary arteriovenous malformations: effects of changes in posture and lung volume
}

\author{
J Ueki, J M B Hughes, A M Peters, G J Bellingan, M A M Mohammed, J Dutton, \\ W Ussov, D Knight, D Glass
}

\begin{abstract}
Background - Patients with arteriovenous malformations are routinely monitored with arterial oxygen saturation $\left(\mathrm{SaO}_{2}\right)$ estimations (breathing air) from which an oxygen shunt fraction can be calculated. This simple estimation has been compared with an anatomically defined estimate of the right to left shunt using a radioisotopic method. The fall in $\mathrm{SaO}_{2}$ which occurs in patients with pulmonary arteriovenous malformations in the erect posture and at high lung volumes was used to test the ability of $\mathrm{SaO}_{2}$ alone to follow changes in right to left shunt.
\end{abstract}

Methods - Radiolabelled albumin macroaggregates ( ${ }^{99 m}$ Tc-MAA) or microspheres (MS) were injected intravenously and kidneys and lungs were imaged. The shunt fraction ( $\mathbf{Q} s / \dot{Q}_{T_{c}}$ ) in the supine position at functional residual capacity (baseline) was obtained by quantifying right kidney radioactivity. On standing or while breath holding at total lung capacity, shunt fraction was calculated from baseline $\dot{Q} s / \dot{Q}_{T_{\mathrm{Tc}}}$ and from lung counts and the injected dose. Arterial oxygen saturation $\left(\mathrm{SaO}_{2}\right)$ was recorded by a pulse oximeter for calculation of the oxygen shunt (Q́s/Q⿱宀 $\mathrm{T}_{\mathrm{O}_{2}}$ ) (breathing air). Results - In the postural study $(n=8)$ $\mathrm{SaO}_{2}$ decreased from a mean (SD) value of 89 (5)\% supine to 80 (6)\% erect, corresponding to Q́s/Q்' $\mathbf{T}_{2} 28(8) \%$ and $44(8) \%$ respectively. Qs $/ \mathbf{Q T}_{\mathrm{Tc}}$ increased from $28 \cdot 7$ $(10 \cdot 3) \%$ to $39(14 \cdot 3) \%$. In the lung volume study $(n=8) \hat{Q} s / \dot{Q} T_{T c}$ increased from 16.6 $(11 \cdot 5) \%$ at functional residual capacity to $23.3(11.9) \%$ at total lung capacity while Q́s/Q $\mathbf{T}_{\mathrm{O}_{2}}$ increased from $19 \cdot 5(7 \cdot 5) \%$ to $25.9(10.6) \%$ respectively. When all measurements were compared for Qs/

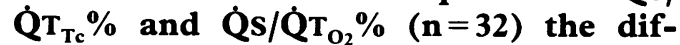
ference in the mean values was $2.5 \%$ (absolute) and the limits of agreement between the two methods were $+38 \%$ to $-18 \%$ (relative). In neither the postural nor the volume study did $\Delta\left(\hat{Q} \mathbf{s} / \dot{Q}_{\mathbf{o}_{2}}\right)$ reliably predict $\Delta\left(\dot{Q} s / \mathbf{Q}_{T_{T c}}\right) \%$.

Conclusions - In pulmonary arteriovenous malformations the simple physiological shunt calculated from $\mathrm{SaO}_{2}$ breathing air agreed well with the anatomical right to left shunt measured with
${ }^{99 m}$ Tc-MAA, but predicted poorly the changes in anatomical shunt induced by postural or lung volume changes.

(Thorax 1994;49:327-331)

Measurements of arterial oxygen saturation $\left(\mathrm{SaO}_{2}\right)$ assist in the diagnosis of pulmonary arteriovenous malformations and in assessing the response to treatment with percutaneous transcatheter embolisation. ${ }^{1}$ The use of $\mathrm{SaO}_{2}$ alone, measured during air breathing, from which an estimate of shunt fraction can be derived, is convenient but not specific for an intrapulmonary anatomical shunt alone, since $\dot{\mathrm{V}} \mathrm{A} / \dot{\mathrm{Q}}$ mismatching from any cause will also lower $\mathrm{SaO}_{2}$.

A more precise estimate of the anatomical intrapulmonary shunt (Q்s/Q́T) can be obtained by measuring arterial $\mathrm{Po}_{2}$ (and haemoglobin) after breathing $100 \%$ oxygen for 15 minutes. ${ }^{2}$ An alternative method involves an intravenous injection of technetium-99m labelled albumin macroaggregates ${ }^{99 \mathrm{~m}} \mathrm{Tc}$ MAA) or microspheres ( ${ }^{99 \mathrm{~m}}$ Tc-MS) $(10-60 \mu \mathrm{m}$ diameter) with gamma camera counting over the lungs and kidneys. ${ }^{3}$ This method provides an anatomically determined estimate of vascular shunts ( $\left.\mathbf{Q} s / \dot{Q}_{\mathrm{T}}{ }_{\mathrm{Anat}}\right)$. In patients with pulmonary arteriovenous malformations there is close agreement between Q́s/Q்T\% calculated by the traditional $100 \%$ oxygen method and the radioisotopic technique. ${ }^{34}$

In practice, the radioisotopic technique is a more convenient way of measuring Q̀s/Q் $\mathrm{T}$ than the $100 \%$ oxygen method for several reasons: (1) there is no arterial blood sampling; (2) complete elimination of alveolar nitrogen, required by the $100 \%$ oxygen technique, is almost impossible to achieve; (3) $100 \%$ oxygen breathing may itself alter the intrapulmonary shunt fraction. In addition, the $100 \%$ oxygen method, in the absence of pulmonary arterial blood sampling, assumes an arteriovenous oxygen content difference of $5 \mathrm{ml} /$ $100 \mathrm{ml}$; thus, it cannot be used in exercise or in unsteady state conditions such as breath holding at full inflation. The ${ }^{99 \mathrm{~m}} \mathrm{Tc}-\mathrm{MAA}$ technique has been adapted for use in exercise ${ }^{3}$ and in other unsteady state conditions.

Nevertheless, for serial measurements it would be better to have an even simpler technique than the intravenous ${ }^{99 \mathrm{~m}} \mathrm{Tc}-\mathrm{MAA}$ method, and one which avoids extra radiation. 
Table 1 Details of patients with pulmonary arteriovenous malformations (PAVMs)

\begin{tabular}{|c|c|c|c|c|c|}
\hline $\begin{array}{l}\text { Patient } \\
\text { no. }\end{array}$ & Sex & $\begin{array}{l}\text { Age } \\
\text { (years) }\end{array}$ & $H H T$ & $\begin{array}{l}\text { PAVMs } \\
\text { (type and location) }\end{array}$ & $\begin{array}{l}\text { Haemoglobin } \\
(\mathrm{g} / \mathrm{dl})\end{array}$ \\
\hline \multicolumn{6}{|c|}{ Postural study } \\
\hline 1 & $\mathbf{M}$ & 41 & + & Small $(M, L)$ & 15.0 \\
\hline 2 & $\mathbf{M}$ & 53 & + & Large $(\mathrm{L})$ & 20.1 \\
\hline 3 & $\mathbf{F}$ & 47 & + & Small (diffuse), large (M,L) & 12.7 \\
\hline 4 & $\mathbf{F}$ & 58 & + & Diffuse $(M, L)$ & 13.3 \\
\hline 5 & $\mathbf{F}$ & 20 & + & Small (diffuse), large $(\mathbf{M})$ & 17.1 \\
\hline 6 & $\mathbf{F}$ & 30 & + & Small (diffuse) & 17.7 \\
\hline 7 & $\mathbf{M}$ & 45 & + & Small (diffuse) & 19.1 \\
\hline 8 & M & 63 & + & Large (diffuse) & 17.1 \\
\hline \multicolumn{6}{|c|}{ Lung volume study } \\
\hline 9 & $\mathrm{~F}$ & 48 & + & Small and large (diffuse) & 8.7 \\
\hline 10 & $\mathbf{M}$ & 65 & - & Large (L) & 15.4 \\
\hline 11 & $M$ & 63 & + & Large (diffuse) & 16.2 \\
\hline 12 & $\mathrm{~F}$ & 34 & + & Small and large $(\mathrm{L})$ & 10.6 \\
\hline 13 & $\mathrm{~F}$ & 49 & + & Large (diffuse) & 8.9 \\
\hline 14 & $\mathbf{M}$ & 43 & + & Small (diffuse) & 13.3 \\
\hline 15 & $\mathbf{M}$ & 32 & + & Large $(M, L)$ & 10.1 \\
\hline 16 & $\mathbf{F}$ & 22 & + & Small (diffuse) & 18.7 \\
\hline
\end{tabular}

HHT = hereditary haemorrhagic telangiectasia; $M=$ mid lung zones; $L=$ lower lung zones.

We have therefore compared estimates of shunt fraction $\left(\dot{\mathrm{Q}} \mathrm{S} / \mathrm{Q}_{\mathrm{O}_{2}}\right)$ from routine measurements of $\mathrm{SaO}_{2}$ (and haemoglobin) breathing air with the more definitive measurement of $\dot{Q} / \mathcal{Q}_{\mathrm{T}}$ ast using the intravenous ${ }^{99 \mathrm{~m}} \mathrm{Tc}-\mathrm{MAA}$ technique. As an additional test, the comparisons were repeated after patients with pulmonary arteriovenous malformations changed from the supine to the erect position or inhaled to high lung volume, manoeuvres which are known to increase the shunt fraction in pulmonary arteriovenous malformations. ${ }^{16}$

\begin{abstract}
Methods
SUBJECTS

Sixteen patients with pulmonary arteriovenous malformations were studied (table 1). In 15 patients pulmonary arteriovenous malformations were associated with hereditary haemorrhagic telangiectasia and all patients had angiographically multiple or small diffuse ( $>2 \mathrm{~mm}$ in diameter) pulmonary arteriovenous malformation communications. The change of shunt fraction with postural change from supine to standing was measured in eight patients (nos 1-8, table 1). In another eight patients (nos 9-16, table 1) the change of shunt fraction with a change of lung volume from functional residual capacity (FRC) to total lung capacity (TLC) was measured. Shunt fraction was measured in eight normal subjects using ${ }^{99 m}$ Tc-MAA to obtain the upper limit of the normal range. Normal values for the ${ }^{99 \mathrm{~m}} \mathrm{Tc}$ MS preparation had already been obtained, ${ }^{4}$ but this particular preparation was unobtainable for the last nine postients studied and ${ }^{99 \mathrm{~m}}$ Tc-MAA was substituted. A further six normal subjects were studied at high and low lung volumes as controls with ${ }^{99 m} \mathrm{Tc}-\mathrm{MAA}$. All subjects gave informed consent to the protocol which was approved by the Hammersmith Hospital research ethics committee.
\end{abstract}

PROTOCOL FOR POSTURAL STUDY

Subjects were asked to remain standing for 10 minutes, after which time ${ }^{99 m}$ Tc-MS (7-25 $\mu \mathrm{m}$; TCK-5-S, CIS, Sorbin Biomedica, Saluggia, Italy; patients $1-7)$ or ${ }^{99 m}$ Tc-MAA $(10-60 \mu \mathrm{m}$;
Amerscan Pulmonate II, Amersham International, Amersham, UK; patient no. 8), mean (SD) 19.7 (8.1) MBq was injected followed by a saline flush. Immediately after the injection images were obtained of the kidneys (posterior view) and lungs (posterior and anterior views) in the supine position. Each image was taken over two minutes. The rest of the MS or MAA $(31.0(10.6) \mathrm{MBq})$ was injected after 10 minutes of lying supine. Both first and second injections were made while subjects breathed quietly around the FRC level. In the same posture, kidneys and lungs were imaged in the same way followed by a lateral kidney image. Arterial oxygen saturation $\left(\mathrm{SaO}_{2}\right)$ and heart rate were recorded every minute using a pulse oximeter (Ohmeda Biox 3700). An International General Electric 400A gamma camera was used, fitted with a parallel hole, general purpose, low energy collimator and on line to a computer (Medical Data System $\mathrm{A}^{2}$ ). The count rate from the right kidney was obtained from a region of interest with minimal inclusion of non-renal tissue. The depth of the kidney was calculated from the number of pixels between the skin marker and the centre of the right kidney on the right lateral image. The count rate from each lung was calculated as the sum of geometric means of the anterior and posterior count rates; the total activity was taken as the sum of the right and left lungs. The injected radioactivity was measured by counting the syringe containing the dose, before and after the injection, on a $3 \mathrm{~cm}$ thick perspex block on the face of the collimated gamma camera. Preliminary experiments had shown that, with an adequate saline flush, the radioactivity trapped in the tubing or needle was negligible. Decay corrections of ${ }^{99 \mathrm{~m}} \mathrm{Tc}$ (half life 360 minutes) were made according to the time at which each image was taken.

\section{PROTOCOL FOR LUNG VOLUME STUDY}

At the beginning of breath holding for 10 seconds at FRC, $29 \cdot 2(4.0) \mathrm{MBq}{ }^{99 m}$ Tc-MAA was injected in the supine position. Immediately after the injection kidneys and lungs were imaged in the same way as in the postural study. Then, in the same posture, the rest of the ${ }^{99 m}$ Tc-MAA $(31 \cdot 7(5 \cdot 1) \mathrm{MBq})$ was injected at the beginning of breath holding at TLC which the subject maintained for 20-30 seconds. All patients were instructed how to avoid a Valsalva manoeuvre. $\mathrm{SaO}_{2}$ and heart rate were recorded every 10 seconds. The kidneys and lungs were imaged in the same way as for the postural protocol followed by the right lateral image. The right kidney and total lung counts, kidney depth, and injected radioactivity were calculated in the same way as described above.

\section{CALCULATION OF THE SHUNT FRACTION} (Q́s/Q̊T)

The right kidney was used in preference to the left, since there was considerable uptake by the spleen. The right kidney counts were corrected for attenuation using the lateral image 
and an attenuation coefficient obtained from previous phantom studies. ${ }^{3}$ The right kidney was assumed to receive $10 \%$ of the systemic cardiac output at rest while breathing quietly at FRC. ${ }^{4}$ Thus :

Qs/Q'T=

$\underline{\text { Right kidney counts } \times 10 \times \text { Attenuation constant }}$ (1) Injected radioactivity

This equation for the calculation of shunt fraction at rest cannot be used for the calculation of shunt fraction when posture or lung volume are altered because fractional kidney blood flow may change transiently. Nevertheless, the change in shunt flow can be related to the change in lung activity, since lung counts reflect the proportion of cardiac output which is not shunted. Total lung counts were obtained in the supine position and related to lung counts in the erect posture or while breath holding at TLC, each being expressed as $\mathrm{MBq} / \mathrm{unit}$ injected dose. The ratio of lung counts $/ \mathrm{MBq}$ (erect or TLC):lung counts/ $\mathrm{MBq}$ (supine) was expressed as a fraction, $\mathrm{f}$. Thus:

$$
\mathrm{f}=\frac{1-Q \mathrm{~s} / \dot{Q} \mathrm{~T}(\text { erect or TLC) }}{1-\mathrm{Q} / \mathrm{QT}(\text { supine or FRC) }}
$$

Therefore:

$$
\text { Q̀s/Q்T (erect or TLC) }=1-\mathrm{f}[1-\text { Q́s/Q́T }
$$$$
\text { (supine or FRC)] }
$$

All shunt values were expressed as fractions. It was not necessary to make an attenuation correction for lung counts because only the change in lung counts $/ \mathrm{MBq}$ injected dose is measured.

In addition, shunt fraction breathing room air was calculated using the classical equation (room air) ${ }^{4}$.

$$
\dot{Q} s / \dot{Q} \mathrm{~T}=\frac{\mathrm{CiO}_{2}-\mathrm{CaO}_{2}}{\mathrm{CiO}_{2}-\mathrm{CvO}_{2}}
$$

assuming $\mathrm{SiO}_{2}$ (oxygen saturation of "ideal" blood) $=98 \%$, and $\mathrm{CaO}_{2}$ (oxygen content of arterial blood) - $\mathrm{CvO}_{2}$ (oxygen content of mixed venous blood) $=5 \mathrm{ml} / 100 \mathrm{ml}$. $\mathrm{Cio}_{2}$ and $\mathrm{CaO}_{2}$ were calculated from $\mathrm{SiO}_{2}$ and $\mathrm{SaO}_{2}$ and haemoglobin; the small dissolved oxygen content in the blood breathing room air was not taken into account.

\section{STATISTICAL ANALYSIS}

All values are expressed as mean (SD). In each group Student's paired $t$ tests compared the values of shunt fraction and $\mathrm{SaO}_{2}$ between the supine and erect positions, and at FRC and at TLC. Linear regression was used to calculate correlation coefficients. Shunt measurements by the oxygen and radioisotope methods were compared using Bland and Altman plots. ${ }^{7}$ Data were logarithmically transformed because the differences between the two methods increased as the shunt size increased.
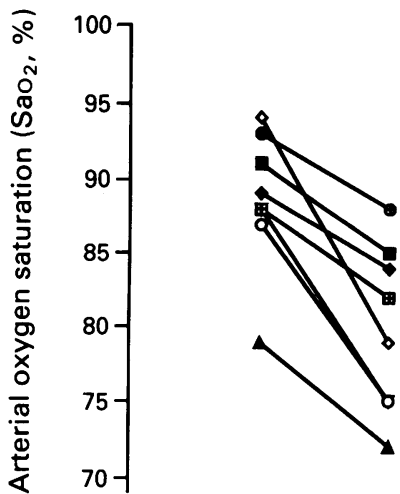

Supine Erect FRC TLC

Figure 1 Arterial oxygen saturation $\left(\mathrm{SaO}_{2}\right)$ in patients with pulmonary arteriovenous malformations in different postures (supine and erect) and lung volumes (FRC and TLC). Symbols identify individual patients.

\section{Results}

SHUNT MEASUREMENT IN NORMAL SUBJECTS

In the eight normal subjects the mean (SD) shunt fraction obtained by the ${ }^{99 m}$ Tc-MAA method was $2.0(1.4) \%$ in the supine position while breathing quietly at FRC. The upper $95 \%$ confidence limit was $3 \cdot 1 \%$. The upper $95 \%$ confidence limit with ${ }^{99 \mathrm{~m}} \mathrm{Tc}-\mathrm{MS}$ in the seated posture, using identical methods and calculations, was previously reported to be $5 \cdot 1 \%{ }^{4}$ There was no significant difference between the results for the two albumin preparations. In a further four normal subjects given ${ }^{99 \mathrm{~m}} \mathrm{Tc}-\mathrm{MAA}$ the shunt fraction at FRC (mean $3.9 \%$, range $3.5-4.2 \%$ ) was no different from that measured at full inflation (TLC) (mean $4 \cdot 05 \%$, range $1 \cdot 8-5 \cdot 8 \%$ ).

SHUNT MEASUREMENTS IN PULMONARY ARTERIOVENOUS MALFORMATIONS

A fall in $\mathrm{SaO}_{2}$ occurred in every patient $(n=16)$ going from supine to erect and from FRC to TLC (fig 1). Mean (SD) values for $\mathrm{SaO}_{2}$ were $89(5) \%$ in the supine posture, $80(6) \%$ erect, $90.5(3.6) \%$ at FRC, and $87(5.5) \%$ at TLC. The oxygen and ${ }^{99 \mathrm{~m}} \mathrm{Tc}-\mathrm{MAA}$ (MS) shunt percentages are shown individually in table 2 . The oxygen and radioisotopic values of $\dot{\mathrm{Q}} / \mathrm{Q} \mathrm{T} \%$ are plotted for the four conditions in fig 2 . There was no significant difference (paired $t$ test) between ${ }^{99 m} \mathrm{Tc}$ and oxygen shunts in any situation (erect, supine, FRC, TLC). The mean difference between $\mathbf{Q} / \hat{Q}_{\mathrm{O}_{2}} \%$ and Q́s/Q́ $\mathrm{T}_{\mathrm{Tc}}$ was + 5\% (erect), - 0.3\% (supine), $+2.9 \%$ (FRC), and $+2.5 \%$ (TLC), with the largest individual difference being $+28.9 \%$ (erect). For all measurements combined, the difference was $+2 \cdot 5 \%$. On a Bland-Altman plot, ${ }^{7}$ with log transformation, the relative difference between the two methods was $6.5 \%$ with limits of agreement $( \pm 2 S D)$ of $+38 \%$ and $-18 \%$. In practical terms an oxygen shunt of $30 \%$ might mean, at worst, a radioisotope shunt varying between $41 \%$ and $25 \%$. For an oxygen shunt of $10 \%$ the true anatomical shunt might lie between $14 \%$ and $8 \%$.

Mean Q́s/Q́ $\mathrm{T}_{\mathrm{O}_{2}}$ increased by $14.5(7 \cdot 1) \%$ from the supine to the erect position compared with an increase of $10.2(5.7) \%$ in $\dot{Q} s / \mathrm{Q}_{\mathrm{Tc}}$. The mean increase in shunt with lung inflation 


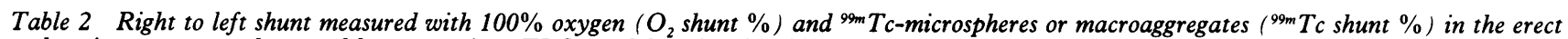
and supine posture, and at total lung capacity (TLC) and functional residual capacity (FRC)

\begin{tabular}{|c|c|c|c|c|c|c|c|c|c|}
\hline \multirow[b]{2}{*}{ Patient no. } & \multicolumn{2}{|l|}{ Erect } & \multicolumn{2}{|l|}{ Supine } & \multirow[b]{2}{*}{ Patient no. } & \multicolumn{2}{|l|}{$T L C$} & \multicolumn{2}{|l|}{$F R C$} \\
\hline & $\mathrm{O}_{2}$ shunt $\%$ & ${ }^{99 m} T c$ shunt $\%$ & $\mathrm{O}_{2}$ shunt $\%$ & ${ }^{99 m} T c$ shunt $\%$ & & $\mathrm{O}_{2}$ shunt $\%$ & ${ }^{99 m} T c$ shunt $\%$ & $\mathrm{O}_{2}$ shunt $\%$ & ${ }^{99 m} T c$ shunt $\%$ \\
\hline $\begin{array}{l}1 \\
2 \\
3 \\
4 \\
5 \\
6 \\
7 \\
8\end{array}$ & $\begin{array}{l}35 \cdot 2 \\
56 \cdot 2 \\
44 \cdot 8 \\
49 \\
43 \cdot 2 \\
40 \cdot 8 \\
50 \cdot 2 \\
32 \cdot 2\end{array}$ & $\begin{array}{l}32 \cdot 6 \\
66 \\
46 \cdot 1 \\
33 \cdot 5 \\
38 \\
48 \cdot 5 \\
21 \cdot 3 \\
25 \cdot 8\end{array}$ & $\begin{array}{l}22 \cdot 6 \\
35 \cdot 8 \\
28 \\
41 \cdot 3 \\
32 \cdot 2 \\
30 \cdot 7 \\
17 \cdot 5 \\
19 \cdot 2\end{array}$ & $\begin{array}{l}20 \cdot 8 \\
44 \cdot 3 \\
32 \cdot 6 \\
25 \cdot 3 \\
34 \\
38 \\
12 \cdot 8 \\
21 \cdot 9\end{array}$ & $\begin{array}{r}9 \\
10 \\
11 \\
12 \\
13 \\
14 \\
15 \\
16\end{array}$ & $\begin{array}{l}21 \\
17 \cdot 6 \\
21 \cdot 3 \\
27 \cdot 7 \\
25 \cdot 8 \\
12 \cdot 9 \\
33 \cdot 6 \\
46 \cdot 9\end{array}$ & $\begin{array}{l}14 \cdot 5 \\
21 \\
14 \\
36 \cdot 5 \\
15 \cdot 6 \\
11 \cdot 9 \\
29 \cdot 1 \\
44 \cdot 1\end{array}$ & $\begin{array}{l}19 \cdot 5 \\
11 \cdot 4 \\
18 \cdot 4 \\
26 \cdot 1 \\
14 \cdot 8 \\
10 \\
23 \cdot 6 \\
31 \cdot 9\end{array}$ & $\begin{array}{c}11 \cdot 9 \\
7 \\
12 \cdot 2 \\
28 \cdot 6 \\
9 \cdot 2 \\
10 \cdot 1 \\
13 \cdot 5 \\
39 \cdot 9\end{array}$ \\
\hline $\begin{array}{l}\text { Mean } \\
\text { SD }\end{array}$ & $\begin{array}{c}44 \\
7.9\end{array}$ & $\begin{array}{l}39 \\
14 \cdot 3\end{array}$ & $\begin{array}{r}28 \cdot 4 \\
8 \cdot 3\end{array}$ & $\begin{array}{l}28 \cdot 7 \\
10 \cdot 3\end{array}$ & $\begin{array}{l}\text { Mean } \\
\text { SD }\end{array}$ & $\begin{array}{l}25 \cdot 9 \\
10 \cdot 6\end{array}$ & $\begin{array}{l}23.3 \\
11.9\end{array}$ & $\begin{array}{r}19 \cdot 5 \\
7.5\end{array}$ & $\begin{array}{l}16 \cdot 6 \\
11.5\end{array}$ \\
\hline
\end{tabular}

(from FRC to TLC) was similar for both techniques - that is, $6 \cdot 4(5 \cdot 1) \%$ for $\mathrm{Q} s / \mathrm{QT}_{\mathrm{O}_{2}}$ and $6.8(5 \cdot 4) \%$ for $\mathrm{Q} s / \mathrm{Q}_{\mathrm{Tc}}$. Nevertheless on an individual patient basis the correlation between $\Delta \dot{Q} / \dot{Q}_{\mathrm{T}_{2}}$ and $\Delta \dot{Q} \mathrm{~s} / \dot{Q}_{\mathrm{T}_{\mathrm{Tc}}}$ was poor (fig 3) with $r=0.27$ (supine to erect) and 0.32 (FRC to TLC).

\section{Discussion}

Pulmonary arteriovenous malformations are a congenital abnormality characterised by a dilated microvasculature giving rise to right to left shunt. ${ }^{89}$ The classical triad of physical signs caused by the shunt consists of cyanosis,

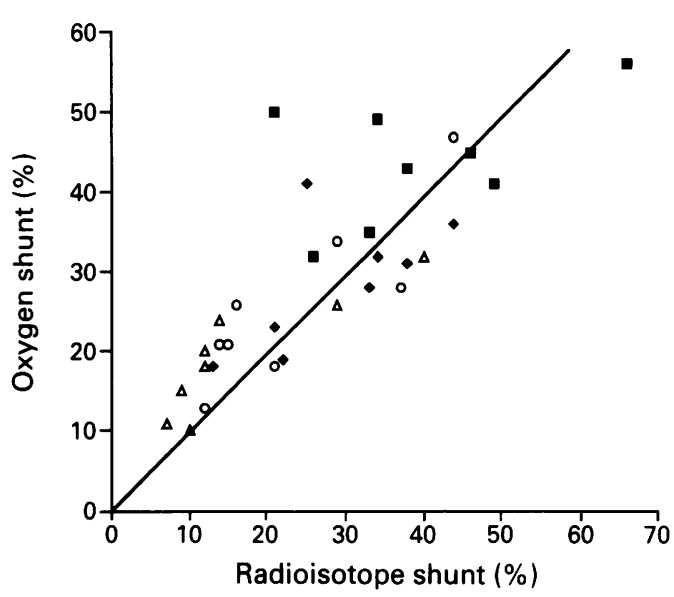

Figure 2 Oxygen right to left shunt plotted against radioisotope shunt in different postures $(\diamond$, supine and , erect) and lung volumes ( $\triangle, F R C$ and $O, T L C)$. Line of identity shown.

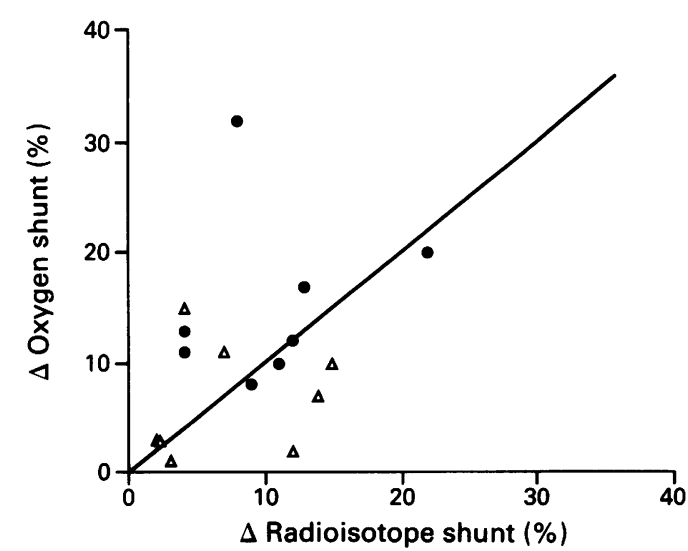

Figure 3 Change in oxygen right to left shunt plotted against change in radioisotope shunt, with change in posture (O, supine to erect) and lung volume ( $\triangle, F R C$ to TLC). Line of identity shown. clubbing, and an overlying bruit. Regardless of size and site of the pulmonary arteriovenous malformations, large or microscopic, single or multiple, arterial oxygenation changes with alterations of posture and lung volume.

\section{COMPARISON OF PHYSIOLOGICAL SHUNT AND} RADIOISOTOPIC SHUNT

The oxygen shunt calculated during air breathing ( $\left.\mathrm{Q} \mathrm{s} / \dot{\mathrm{Q}}_{\mathrm{O}_{2}}\right)$, also called the "venous admixture" effect, although not as specific for anatomical shunting as the $100 \%$ oxygen shunt, showed good agreement with a specific index of anatomical shunt ( $\left.\dot{Q} \mathrm{~s} / \hat{Q}_{\mathrm{T}_{\mathrm{C}}}\right)$. This means that routine measurements of $\mathrm{SaO}_{2}$ (scaled for $[\mathrm{Hb}]$ to give arterial oxygen content) would be a reasonable substitute for the radioisotopic method in monitoring the intrapulmonary shunt in pulmonary arteriovenous malformations. The accuracy of $\mathrm{SaO}_{2}$ measurements is $\pm 2 \%,{ }^{10}$ and this could introduce errors of up to $6 \%$ in the absolute oxygen shunt estimate. Unfortunately, the oxygen shunt while breathing air is not a robust enough measurement to predict changes in the antomical shunt in unsteady state conditions associated with postural or lung volume change (fig 3), nor could it be used in exercise. ${ }^{4}$

OXYGEN DESATURATION IN THE ERECT POSTURE All eight patients with pulmonary arteriovenous malformations showed arterial oxygen desaturation and an increase in right to left shunt on standing erect (fig 1). In five patients there was good agreement between the change in the oxygen shunt and the change in the albumin microsphere/macroaggregate shunt (table 2), implying that all their postural desaturation could be explained by an increase in shunt flow through the pulmonary arteriovenous malformations.

In three patients whose increase in oxygen shunt exceeded the increase in albumin microsphere/macroaggregate shunt, the shunts were in good agreement in the supine posture (table 2, patients 5-7). Possible explanations in these three cases include an increase in dispersion of ventilation/perfusion ratios in the erect posture, or a fall in mixed venous oxygen saturation, or both. A progressive fall in mixed venous oxygen content while standing erect would be associated with a steady fall in $\mathrm{SaO}_{2}$ on the pulse oximetry readings (assuming a constant right to left shunt fraction). The 
average fall of $\mathrm{SaO}_{2}$ from the second to the tenth minute, while the subjects stood erect to stabilise $\mathrm{SaO}_{2}$ before the shunt measurement, was $1 \cdot 38 \%$. Two patients had large falls $(3 \%$ and $4 \%$ ), the largest fall being in the patient with the biggest discrepancy between oxygen and radioisotope shunts. The evidence is inconclusive, but cardiovascular instability was probably the cause of the difference between the oxygen and radioisotope shunt estimates of shunt in the erect posture in one subject; an increase in $\dot{V} / Q$ mismatching might have contributed in the other two subjects.

In four patients (nos 1-4) the pulmonary arteriovenous malformations were predominatly located in the mid and lower lung zones. The right to left shunt fraction tended to increase more in them from supine to erect (table 2) than in patients 5-8 with more diffuse pulmonary arteriovenous malformations (table 1). Thus a gravitational shift in pulmonary blood flow and the caudal location of the pulmonary arteriovenous malformation channels probably explain the increase in right to left shunt which is associated with a change from the supine to the erect posture.

OXYGEN DESATURATION WITH LUNG INFLATION In an earlier report ${ }^{6}$ the relative increase in the anatomical shunt in patients with pulmonary arteriovenous malformations $(n=8)$ who breath held at TLC (100\% oxygen method) was $25 \%$. The relative increase in physiological shunt in our eight patients was $33 \%$, slightly less than the relative increase in the true anatomical shunt as measured by ${ }^{99} \mathrm{~m} \mathrm{Tc}-$ MAA ( $40 \%$ increase).

Does this increase tell us about the site of the abnormal vascular channels? As already mentioned, the normal microvasculature is replaced in pulmonary arteriovenous malformations by a sac of very low vascular resistance. The artery and vein to and from these sacs are enlarged "physiologically" in response to the high flow through the low resistance conduit. Pulmonary vessels can be divided physiologically into alveolar and extra-alveolar vessels, the former being in the alvelolar septa and the latter comprising corner vessels and all intrapulmonary arterial and venous vessels. Alveolar vessels become smaller and extra-alveolar vessels become bigger as lung volume in- creases. If pulmonary arteriovenous malformations behaved as alveolar vessels a decrease in right to left shunt might be expected with lung inflation. This was not the case. A diffuse dilatation of alveolar septal vessels does occur - for example, in the hepatopulmonary syndrome $^{11}$ - accompanied by a radioisotopic shunt which exceeds considerably the shunt on breathing $100 \%$ oxygen $\left(45 \% v 13 \%{ }^{12}\right)$, a situation not found in pulmonary arteriovenous malformations. ${ }^{4}$ It therefore seems more likely that pulmonary arteriovenous malformations are behaving as extra-alveolar vessels.

Nevertheless, the crucial factor is the difference in resistance between the normal arterial-capillary-venous conduit and the pulmonary arteriovenous malformation conduit, both conduits comprising alveolar and extra-alveolar vessels. The radioisotope data suggest that, even if the resistance of the pulmonary arteriovenous malformation conduit increases with lung inflation, the resistance of the normal vascular conduit in parallel increases more.

1 Chilvers ER, Whyte MKB, Jackson JE, Allison DJ, Hughes JMB. Effect of percutaneous transcatheter embolization on pulmonary function right to left shunt, and arterial oxygenation in patients with pulmonary arteriovenous malformations. Am Rev Respir Dis 1990;142:420-5.

2 Berrgren SM. The oxygen deficit of arterial blood caused by non-ventilating parts of the lung. Acta Physiol Scand non-ventilating parts
1942;4(Suppl II): $1-92$.

3 Chilvers ER, Peters AM, George P, Hughes JMB, Allison DJ. Quantification of right to left shunt through pulmonary arteriovenous malformations using ${ }^{99 \mathrm{~m}} \mathrm{Tc}-\mathrm{MAA}$ albumin microspheres. Clin Radiol 1988;39:611-4.

4 Whyte MKB, Peters AM, Hughes JMB, Henderson BL, Bellingham GJ, Jackson JE, et al. Quantification of right to left shunt at rest and during exercise in patients with pulmonary arteriovenous malformations. Thorax 1992; 47:790-6.

5 Harris EA, Kenyon AM, Nisbet HD, Seelye ER, Whitlock RML. The normal alveolar-arterial oxygen tension gradiRML. The normal alveolar-arterial oxy

6 Huseby JS, Culver BH, Butler J. Pulmonary arteriovenous fistulas: increase in shunt at high lung volume. $A m R e v$ Respir Dis 1977;115:229-32.

7 Bland JM, Altman DG. Statistical methods for assessing agreement between two methods of clinical measurement. Lancet 1986; i:307-10.

8 Dines DE, Seward JB, Bernatz PE. Pulmonary arteriovenous fistulas. Mayo Clin Proc 1983;58:176-81.

9 Burke CM, Safali C, Nelson DP, Raffin TA. Pulmonary arteriovenous malformations: a critical update. Am Rev Respir Dis 1986;134:334-9.

10 Nickerson BG, Sarkisian C, Tremper K. Bias and precision of pulse oximeters and arterial oximeters. Chest 1988;93:515-7.

11 Rodriguez-Roisin R, Agusti A, Roca J. The hepatopulmonary syndrome; new name, old complexities. Thorax 1992;47:897-902.

12 Genovesi MG, Tierney DF, Taplin GV, Eisenberg H. An intravenous radionuclide method to evaluate hypoxemia caused by abnormal alveolar vessels. Am Rev Respir Dis 1976;114:59-65. 